\title{
Measuring Mosquito Diversity Patterns in an Amazonian Terra Firme Rain Forest
}

Author(s): G. R. Julião, F. Abad-Franch, R. Lourenço-De-Oliveira, and S.L.B. Luz Source: Journal of Medical Entomology, 47(2):121-128. 2010.

Published By: Entomological Society of America

DOI: 10.1603/ME09060

URL: http://www.bioone.org/doi/full/10.1603/ME09060

BioOne (www.bioone.org) is an electronic aggregator of bioscience research content, and the online home to over 160 journals and books published by not-for-profit societies, associations, museums, institutions, and presses.

Your use of this PDF, the BioOne Web site, and all posted and associated content indicates your acceptance of BioOne's Terms of Use, available at www.bioone.org/page/terms of use.

Usage of BioOne content is strictly limited to personal, educational, and non-commercial use. Commercial inquiries or rights and permissions requests should be directed to the individual publisher as copyright holder. 


\title{
Measuring Mosquito Diversity Patterns in an Amazonian Terra Firme Rain Forest
}

\author{
G. R. JULIÃO,$^{1}$ F. ABAD-FRANCH,${ }^{1}$ R. LOURENÇO-DE-OLIVEIRA, ${ }^{2}$ AND S.L.B. LUZ ${ }^{1}$
}

Instituto Leônidas e Maria Deane-Fiocruz Amazônia, Rua Teresina 476, 69.057-070, Manaus, Amazonas, Brazil

J. Med. Entomol. 47(2): 121-128 (2010); DOI: 10.1603/ME09060

\begin{abstract}
We reanalyzed a dataset consisting of $\approx 10,700$ crepuscular and night-biting female mosquitoes (Culicidae) collected over 12 mo in the canopy and understorey of primary Amazonian rain forest. We investigate whether vertical habitat stratification and rainfall modified major ecological parameters of this mosquito ensemble, combining descriptive and hypothesis-testing statistics with species richness and diversity metrics in the analyses. A total of 31 species was recorded. Contrary to expectations, the host-seeking mosquito fauna was less diverse in the forest canopy than in the understorey. In particular, species diversity and evenness were higher in understorey samples, whereas species richness estimates were similar in both habitats. Only two out of 12 species tested for vertical stratification were clearly acrodendrophilic, and five preferred understorey habitats. The mosquito fauna was more diverse in the rainy than in the dry season. We propose the hypothesis that female mosquito density and host defensive behavior may promote host seeking in nonpreferred habitats by acrodendrophilic mosquito species. These results may be particularly relevant for understanding the dynamics of Plasmodium malariae/brasilianum and arboviral infections in Amazonian forested landscapes.
\end{abstract}

KEY WORDS Culicidae, Anophelinae, vector ecology, Amazonia

Hematophagous female mosquitoes (Diptera: Culicidae) act as vectors of infectious disease agents of humans and other animals. Several major parasites (such as those causing malaria or lymphatic filariasis) and arboviruses (such as dengue, yellow fever, or West Nile viruses) are transmitted by mosquito bites (Beaty and Marquardt 1996, Cook 1996). The estimated global burden of human mosquito-borne infectious diseases reached 47.5 million disability-adjusted life years (DALYs) in 2001; this figure represented $\approx 15 \%$ of all DALYs lost because of infectious and parasitic diseases worldwide (Mathers et al. 2006).

Nearly 200 arbovirus species are known to circulate in the Brazilian Amazon (Vasconcelos et al. 2001), and over 500,000 cases of malaria are reported each year from the region (Tadei et al. 1998). With a few exceptions (e.g., introduced Aedes aegypti L.), disease transmission cycles involve native mosquitoes, either when humans enter forest environments or because some local vector species successfully adapt to human landscapes (Tadei et al. 1998, Vasconcelos et al. 2001, Hutchings et al. 2005a). However, and as for many other arthropod groups, the true diversity of mosquito

\footnotetext{
${ }^{1}$ Instituto Leônidas e Maria Deane-Fiocruz Amazônia, Rua Teresina 476, 69.057-070, Manaus, Amazonas, Brazil (e-mail: sergioluz@amazonia.fiocruz.br).

${ }^{2}$ Laboratório de Transmissores de Hematozoários, Instituto Oswaldo Cruz-Fiocruz, Avenida Brasil 4365, 21.045-900 Rio de Janeiro, RJ, Brazil.
}

species in the Amazon remains unknown. Of the 447 species known from Brazil (Foley et al. 2007), $\approx 200$ have been recorded in the Brazilian state of Amazonas (Natal et al. 1992, Lourenço-de-Oliveira and Luz 1996, Luz and Lourenço-de-Oliveira 1996, Fé et al. 2003, Hutchings et al. 2005a,b).

In the current study, we reassess a dataset consisting of $\approx 10,700$ host-seeking female mosquitoes collected over $1 \mathrm{yr}$ in both the canopy and understorey of a primary Amazonian rain forest (Lourenço-de-Oliveira and Luz 1996, Luz and Lourenço-de-Oliveira 1996). Moving beyond the original descriptive appraisal, we asked whether vertical habitat stratification and rainfall modified major ecological parameters of this forest mosquito fauna. We combined descriptive and hypothesis-testing statistics with diversity metrics depicting species richness, heterogeneity, and evenness. Thus, we were able to provide a quantitative assessment of spatial and temporal variation in species diversity that was not presented in the original reports. In addition, and for the most common species, we formally tested whether and how canopy and understorey catches departed from random expectations; the results provide new information on species-specific preferential host-seeking activity. Because of the greater host variety and biomass in the rain forest canopy (Erwin 2001, de Thoisy et al. 2003), we expected mosquito diversity and abundance to be higher in the canopy than in the understorey. We also ex- 
Table 1. Rainfall classes (months, rainfall mean \pm SD) and no. of mosquitoes collected in canopy and understorey habitats at the Samuel Ecological Station, Rondônia, Brazil (1990-1991)

\begin{tabular}{|c|c|c|c|c|}
\hline \multirow{2}{*}{$\begin{array}{c}\text { Rainfall } \\
\text { classes }\end{array}$} & \multirow{2}{*}{ Months } & \multirow{2}{*}{$\begin{array}{l}\text { Rainfall } \\
(\mathrm{mm})\end{array}$} & \multicolumn{2}{|c|}{ Mosquitoes (n) } \\
\hline & & & Canopy & Understorey \\
\hline Is & Aug.-Oct. & $153.2 \pm 117.8$ & 1,019 & 670 \\
\hline ERs & Nov.-Jan. & $296.3 \pm 45.5$ & 233 & 526 \\
\hline LRs & Feb.-April & $305.2 \pm 77.7$ & 1,203 & 1,349 \\
\hline Ds & May-July & $60.2 \pm 34.8$ & 4,130 & 1,519 \\
\hline Total & & & 6,585 & 4,064 \\
\hline
\end{tabular}

Is, intermediate season; ERs, early rainy season; LRs, late rainy season; Ds, dry season.

pected to observe an overall pattern in which freshwater mosquito diversity and abundance are strongly influenced by rainfall, reflecting the requirements of aquatic immature stages (Service 1993, Bates 1949). For instance, species that breed in still water pools (e.g., Anopheles forattinii [Wilkerson and Sallum]) should become more abundant in the early dry season (Ds), whereas phytotelmata-breeding species (e.g., Hemagogus and several Sabethini) should benefit from heavy rain periods, and these differences should translate into distinct species diversity and abundance signatures.

\section{Materials and Methods}

Study Area and Data. The original data were gathered at the Samuel Ecological Station $\left(8^{\circ} 10^{\prime} \mathrm{S}, 62^{\circ}\right.$ $29^{\prime} \mathrm{W}$ ), a permanently protected area of primary terra firme (nonflooded) rain forest in northwestern Amazonia (state of Rondônia, Brazil). Mosquito collection was performed from August 1990 to July 1991 in three replicate sampling stations, $\approx 1 \mathrm{~km}$ from each other and consisting of one ground-level (understorey) and one canopy (tree platforms 15-17 m above ground) sampling points. Two collectors worked simultaneously in understorey and canopy habitats from 6 to 9 p.m., capturing specimens landing on their exposed legs with a manual aspirator. They switched positions in each sampling occasion. Captures occurred daily, except on heavy rain nights; at least three captures were conducted per week regardless of weather conditions. Further methodological details can be found in the original papers (Lourenço-de-Oliveira and Luz 1996, Luz and Lourenço-de-Oliveira 1996); the dataset was complemented with unpublished information (S.L.B. Luz and R. Lourenço-de-Oliveira), and is available in its final form on request from the corresponding author. The designation An. mediopunctatus sensu lato used in Lourenço-de-Oliveira and Luz (1996) was changed here to An. forattinii (Wilkerson and Sallum 1999), which is now known to be the dominant member of the An. mediopunctatus cryptic species group in northwestern Amazonia (see Wilkerson and Sallum 1999, Hutchings and Sallum 2001).

Data Analysis. Canopy and understorey records from the three sampling stations were treated as single pools to test habitat effects. Four rainfall classes (see Table 1), each encompassing three calendar months, were defined to test rainfall effects on the host-seeking mosquito fauna. Following analytical procedures recommended by Krebs (1989), diversity was assessed by combining measures of species richness (absolute number of species), heterogeneity (based on the number of species and their relative abundance), and evenness (how individuals are distributed among species). Individual-based rarefaction curves were used to estimate and compare both the absolute number $\left(S_{R}\right.$, species richness) and the density $\left(S_{D}\right)$ of mosquito species between habitats and among rainfall classes (Gotelli and Colwell 2001); in our case, $S_{D}$ corresponds to the observed number of species in each spatial (canopy/understorey) or temporal (rainfall) sample. Rarefaction-based estimates and 95\% confidence intervals (CIs) were computed with the software Analytical Rarefaction 1.3 (Holland 2003). The Shannon diversity index (denoted $H^{\prime}$ ) was used as a measure of community heterogeneity (Krebs 1989); evenness was estimated as $E_{H}^{\prime}=H^{\prime} / H_{\max }$, where $H_{\text {max }}=\ln S_{D}$. Mosquito species were ranked by their log-transformed abundance (defined as the number of individuals captured in a given rainfall class or habitat) to assess how individuals were distributed among species in the spatial and temporal scales under consideration. These relationships were graphically represented in "rank log-abundance plots" (Krebs 1989). The fit of the data to a log-normal curve was tested by means of Lilliefors tests computed in SYSTAT 8.0 (SPSS Inc.); fit measures included the maximum absolute difference between empirical and theoretical distributions ("max-dif") and $P$ values derived from a goodness-of-fit Kolmogorov-Smirnov test (Zar 1999). A good fit to a log-normal curve indicates that just a few species are either extremely abundant or extremely rare, with the majority of them appearing with intermediate abundance values; it has been suggested that this is the expected pattern for well-sampled species ensembles that are at equilibrium with respect to niche space (Sugihara et al. 2003). However, a better fit to the log-series emerges when several species are rare in the assemblage, while only a few are abundant (Krebs 1989, Magurran 1996, 2004). Finally, and for the 12 most abundant species, we compared log-abundance in canopy and understorey catches with paired (by month) $t$-tests or nonparametric rank-sum tests with a blocking variable (month) when normality or homoscedasticity were dubious; these tests were implemented in JMP 4.0.2 (SAS Institute, Cary, NC).

\section{Results}

A total of 10,649 host-seeking female mosquitoes (Culicinae and Anophelinae) was collected, and 31 species within 11 genera were identified (Lourençode-Oliveira and Luz 1996, Luz and Lourenço-de-Oliveira 1996). The most abundant species were An. forattinii (46.7\% of all catches), Ae. fulvus (Wiedemann) (8.6\%), An. shannoni Davis (8.1\%), An. nuneztovari Gabaldon (7.0\%), Ae. pennai Antunes and Lane (4.5\%), and Psorophora dimidiata Cerqueira (4.3\%). 
Table 2. Mosquito diversity metrics in two habitats (canopy and understorey) and four rainfall classes (as defined in Table 1) at one Amazonian terra firme rainforest site in Brazil (Samuel Ecological Station, Rondônia)

\begin{tabular}{|c|c|c|c|c|c|c|}
\hline \multirow{2}{*}{ Diversity metric } & \multicolumn{2}{|c|}{ Habitats } & \multicolumn{4}{|c|}{ Seasons } \\
\hline & Canopy & Understorey & Intermediate & Early rainy & Late rainy & Dry \\
\hline Species diversity (Shannon $H^{\prime}$ ) & 1.40 & 2.63 & 1.40 & 2.33 & 2.34 & 1.56 \\
\hline Species evenness (Shannon $E_{H}^{\prime}$ ) & 0.42 & 0.78 & 0.48 & 0.75 & 0.71 & 0.50 \\
\hline Species richness $\left(S_{R}\right)$ & 26.7 (a) & $29(\mathrm{~b})$ & $16.3(\mathrm{a})$ & $22(\mathrm{c})$ & $23.9(\mathrm{~d})$ & $19.9(\mathrm{~b})$ \\
\hline$S_{R} 95 \% C I$ & $24.3-29.1$ & $28.9-29.1$ & $13.8-18.7$ & $21.8-22.1$ & $21.6-26.5$ & $17.9-21.9$ \\
\hline Species density $\left(S_{D}\right)$ & $29(\mathrm{c})$ & $29(\mathrm{~b})$ & $19(\mathrm{e})$ & $22(\mathrm{c})$ & $27(\mathrm{~g})$ & $23(\mathrm{f})$ \\
\hline
\end{tabular}

Letters in brackets indicate the values of species density and richness presented in Figure 1 (habitats) and Figure 3 (seasons).

Spatial Variation: Canopy and Understorey HostSeeking Mosquitoes. Species diversity $\left(H^{\prime}\right)$ and evenness $\left(E_{H}^{\prime}\right)$ were both higher in understorey than in canopy samples, whereas species density estimates were identical $\left(S_{D}=29\right)$ (Table 2 ; Fig. 1 ). Twentyseven species $(87 \%)$ were shared by both habitats, and all four species unique to a single habitat were represented by only one individual. Total abundance was higher in the canopy ( $N c=6,585$ individuals) than in the understorey $(\mathrm{N} u=4,064)$ (Table 1). Individualbased rarefaction curves suggested that, for equal sample sizes, species richness $\left(S_{R}\right)$ might be slightly lower in canopy than in understorey habitats, but $95 \%$ CIs consistently overlapped across $\mathrm{x}$-axis values (number of individuals) (Fig. 1).

Rank log-abundance plots showed that $83 \%$ of canopy species were represented by $<100$ individuals, and $34.5 \%$ by $<10$ individuals (Fig. 2 ). These proportions were lower for understorey samples $(62 \%$ and $31 \%$, respectively), resulting in a different curve shape for each habitat. Canopy abundance (log-transformed) data fitted a log-normal distribution (Lilliefors test max-dif $=0.117$; Kolmogorov-Smirnov $P=$ 0.756) better than understorey data did (max-dif $=$ $0.146 ; P=0.114$ ). The number of singletons (rare species represented by a single individual) was identical in both habitats (Fig. 2) .

Higher host-seeking mosquito abundance in the canopy was largely because of An. forattinii (4,276 individuals, or $65 \%$ of all canopy catches). An. forattinii was the most abundant mosquito also in the understorey (700 individuals), but contributed only $17.2 \%$ to the total number of specimens caught in this habitat. Paired tests suggested that An. forattinii and An. shannoni were the only truly acrodendrophilic (canopyfeeder) species in our sample. Putative understoreyspecialist taxa were Ae. serratus, Culex bastagarius Dyar and Knab, Culex (Melanoconion) spp., Ps. dimidiata, and Coquillettidia lynchi (Shannon). Ae. fulvus was almost equally abundant in both habitats; a similar pattern of no habitat use bias was recorded for other species in four genera. These results are summarized in Table 3.

Temporal Variation: Host-Seeking Mosquitoes and Rainfall. Mosquito catches varied markedly among rainfall classes, ranging from 759 (Early rainy season, ERs) to 5,649 individuals dry season (Ds) (Table 1). Rarefactionbased species richness and density estimates were also significantly affected by precipitation (Fig. 3) . Limit 95\% CI values overlapped between intermediate season/ early rainy season (Is/ERs) and between late rainy season/dry season (LRs/Ds) at low $x$ values.

Overall, $S_{R}$ was significantly lower in Is than in ERs and LRs, but did not differ significantly from Ds (Table 2). $S_{D}$ values decreased along the sequence LRs $\rightarrow$ Ds $\rightarrow$ ERs $\rightarrow$ Is. However, both rarefaction-derived $S_{R}$ and Shannon $H^{\prime}$ suggested that the mosquito fauna was more diverse in the ERs than in the Ds (Fig.

Table 3. Patterns of observed abundance of the 12 most commonly caught crepuscular- and night-biting mosquito species in the canopy and understorey of the Samuel Ecological Station, Rondônia, Brazil

\begin{tabular}{|c|c|c|c|c|c|}
\hline \multirow{2}{*}{ Species } & \multicolumn{2}{|c|}{ Habitat } & \multirow{2}{*}{ Statistics } & \multicolumn{2}{|c|}{ N-PH use } \\
\hline & Canopy & Understorey & & High-density & Low-density \\
\hline An. (Anopheles) forattinii & $4,276(85.9 \%)$ & $700(14.1 \%)$ & $t=13.01, \mathrm{df}=11, P<0.0001$ & $16.6 \%$ & $8.8 \%$ \\
\hline An. (Anopheles) shannoni & $683(79.0 \%)$ & $182(21.0 \%)$ & $\chi^{2}=16.4, \mathrm{df}=1, P<0.0001$ & $22.5 \%$ & $16.8 \%$ \\
\hline Ps. (Grabhamia) dimidiata & $24(5.2 \%)$ & $439(94.8 \%)$ & $t=-6.8, \mathrm{df}=11, P<0.0001$ & \multicolumn{2}{|c|}{ Seasonal (late rainy-dry) } \\
\hline Ae. (Ochlerotatus) serratus & $65(18.0 \%)$ & $296(82.0 \%)$ & $t=-7.7, \mathrm{df}=11, P<0.0001$ & $20 \%$ & $13.8 \%$ \\
\hline Cq. (Rhynchotaenia) lynchi & $21(5.8 \%)$ & $344(94.2 \%)$ & $t=-5.7, \mathrm{df}=11, P<0.0001$ & \multicolumn{2}{|c|}{ Seasonal (late rainy-early dry) } \\
\hline Cx. (Melanoconion) bastagarius & $70(20.0 \%)$ & $281(80.0 \%)$ & $\chi^{2}=17.3, \mathrm{df}=1, P<0.0001$ & $22.2 \%$ & $17.2 \%$ \\
\hline Cx. (Melanoconion) spp. & $19(10.5 \%)$ & $162(89.5 \%)$ & $\chi^{2}=7.96, \mathrm{df}=1, P=0.005$ & \multicolumn{2}{|c|}{ Erratic } \\
\hline Ae. (Ochlerotatus) fulvus & $500(53.6 \%)$ & $432(46.4 \%)$ & Not significant & \multicolumn{2}{|c|}{-} \\
\hline An. (Nyssorhynchus) nuneztovari & $435(58.0 \%)$ & $315(42.0 \%)$ & Not significant & \multicolumn{2}{|c|}{-} \\
\hline Ae. (Ochlerotatus) pennai & $139(29.3 \%)$ & $336(70.7 \%)$ & Not significant & \multicolumn{2}{|c|}{-} \\
\hline Cx. (Melanoconion) chrysonotum & $84(34.3 \%)$ & $161(65.7 \%)$ & Not significant & \multicolumn{2}{|c|}{-} \\
\hline Ps. (Janthinosoma) albipes & $61(42.0 \%)$ & $84(58.0 \%)$ & Not significant & \multicolumn{2}{|c|}{-} \\
\hline
\end{tabular}

Bold figures denote significantly higher abundance values (after paired $t$-tests or nonparametric rank-sum tests with a blocking variable [month] on log-transformed data), interpreted here as evidence of habitat specialization. N-PH use denotes the pattern of use of non-preferred habitats by putative specialist taxa; the overall percentage of host-seeking females in the N-PH during high- and low-density periods (see text for details) is given for species showing a density-related pattern, and a brief description of other patterns is given for the rest of species. 


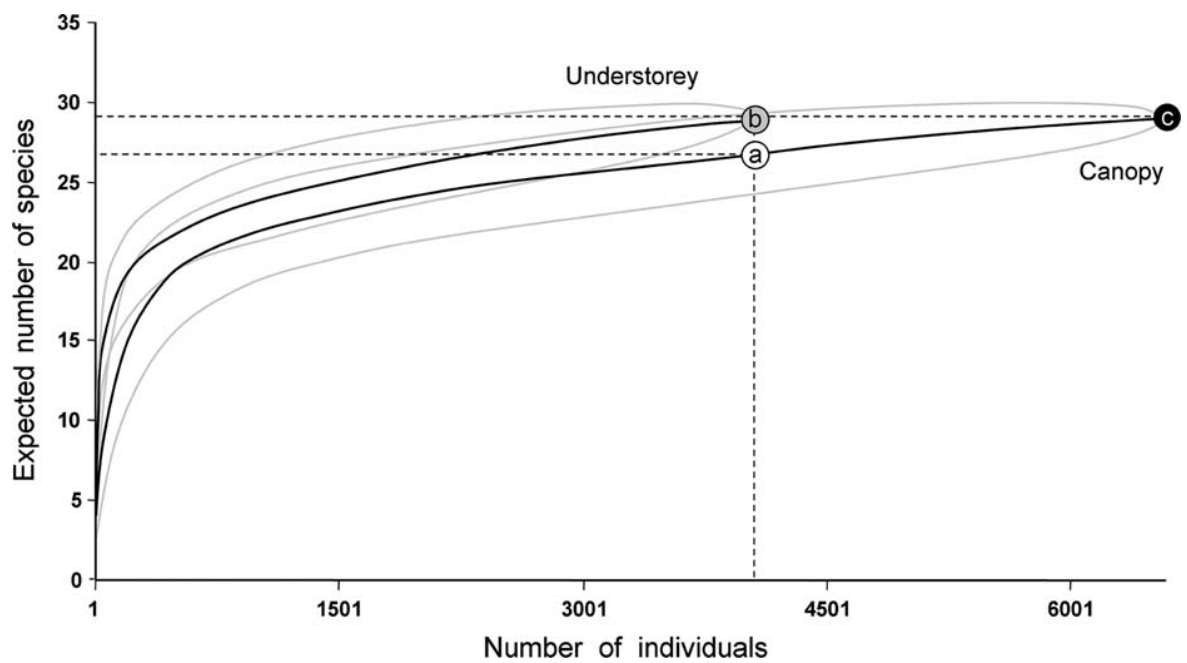

Fig. 1. Individual-based rarefaction curves for canopy and understorey mosquito species (solid black lines) and 95\% CL (gray lines). Species density is the estimated number of species in each habitat. Species richness (estimated number of species in each habitat given equal sample sizes) was rarefied to the number of individuals of the habitat with lowest mosquito abundance (understorey) $\mathrm{a}=$ species richness estimate for canopy mosquitoes; $\mathrm{b}=$ observed species density for understorey mosquitoes; $\mathrm{c}=$ observed species density for canopy mosquitoes.

3; Table 2). Mosquito individuals were more evenly distributed among species during the rainy season (ERs and LRs) than in either the dry or the intermediate seasons (Table 2). This effect was largely because of the dominance of An. forattinii in both canopy and understorey habitats in drier months (Is, 1,082 individuals or $64.1 \%$ of all catches; and Ds, 3,361 individuals or $59.5 \%$ of catches). Cx. bastagarius was the most abundant species in ERs, with 147 specimens (19.4\%), and Ae.fulvus (673 individuals, 26.4\%) in LRs.

Further indications that weather influences mosquito fauna structure were obtained from rank logabundance plot analysis (Fig. 2). The shape of the log-transformed abundance curves varied noticeably among rainfall classes: it was nearly linear in Is (Lilliefors test, max-dif $=0.136$; Kolmogorov-Smirnov $P=$ 0.484 ) and ERs (max-dif $=0.129 ; P=0.446$ ), and approached a log-normal distribution in LRs (maxdif $=0.092 ; P=0.881$ ) and Ds (max-dif $=0.117 ; P=$ $0.577)$.

Host-Seeking Mosquito Density and Height Preferences. We preliminarily explored the possible effects of species-specific density on the proportion of hostseeking mosquitoes caught in nonpreferred habitats. For this tentative assessment, we selected the seven species that showed a significant habitat preference in the vertical gradient (see Table 3 and above). We considered two alternative scenarios: active habitat shift and passive spill-over. In the first case, females of habitat-specialist taxa actively search for food in nonpreferred habitats during high-density periods, when the amount of blood available per individual is lower (e.g., because of increased bite-related irritability of hosts) (Edman and Scott 1987, Sota et al. 1991, Kelly 2001, Darbro and Harrington 2007). Thus, the proportion of catches in nonpreferred habitats should increase in periods of higher density. In the second case, the proportion of host-seeking mosquitoes in the nonpreferred habitat would remain stable whatever the number of catches in the preferred habitat. For An. forattinii, understorey (nonpreferred habitat) monthly catches increased proportionally to canopy catches only at low density values; when canopy catches were $>450$ individuals, the fraction of hostseeking females caught in the nonpreferred habitat was disproportionately large (Fig. 4), reaching $22.7 \%$ in the mid-Ds (July) versus a maximum of $14.5 \%$ in low-density months (February). Overall, the proportion of An. forattinii catches at ground level was almost double $(16.6 \%)$ during high-density periods (catches $>500$ individuals/mo) than during low-density periods $(8.8 \%)$. Similar but weaker patterns were detected for Ae. serratus (Theobald) (high-density period defined as catches $>75$ individuals $/ \mathrm{mo}$ ) and An. shannoni (high-density period, catches $>195$ individuals/mo) (Table 3). Cx. bastagarius catches in preferred and nonpreferred habitats were roughly proportional, suggesting spill-over. Both Ps. dimidiata and Cq. lynchi tended to use nonpreferred (canopy) habitats during certain rainfall classes, independently of abundance patterns. Culex (Melanoconion) spp. seemed to appear in canopy catches in a nearly random way, which may be because of the inclusion of two or more cryptic entities within this taxon.

\section{Discussion}

Our reassessment revealed some patterns of variation that went unnoticed in the original analyses, and confirmed others. Our quantitative appraisal included both culicine and anopheline species, which were treated separately in the original reports (Lourençode-Oliveira and Luz 1996, Luz and Lourenço-de-Oliveira 1996); this allowed for a more comprehensive 


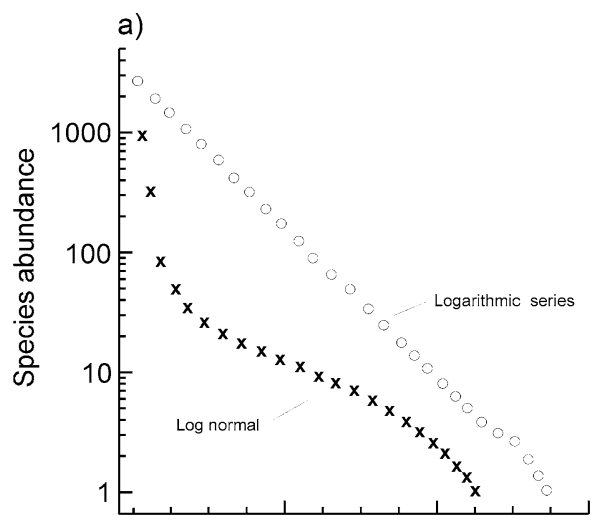

c)

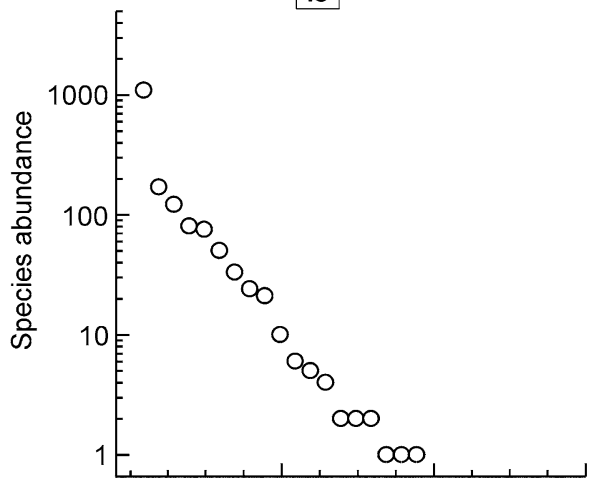

e)

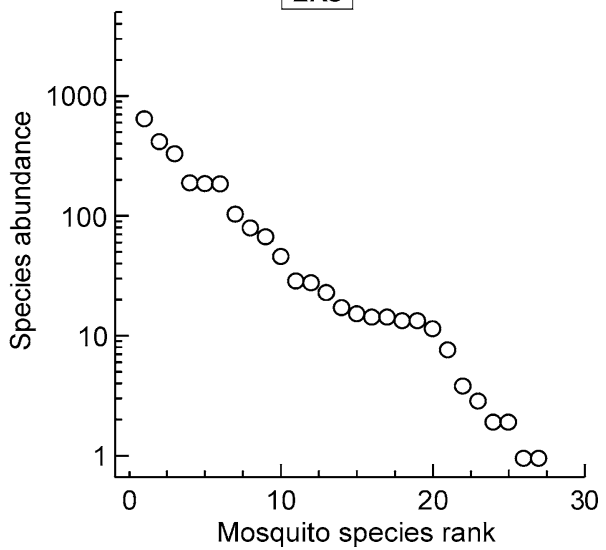

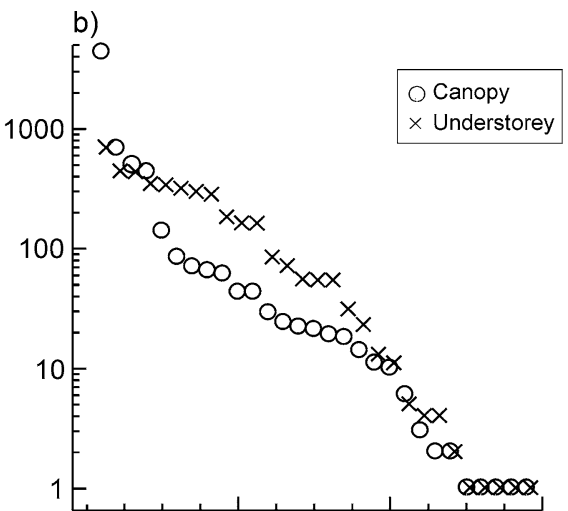

d)

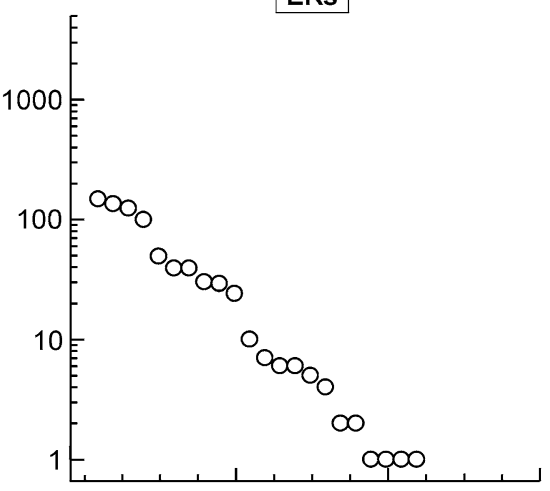

f)

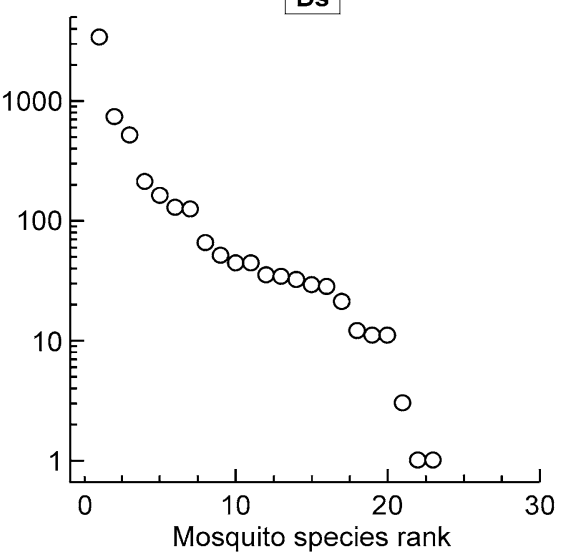

Fig. 2. Rank log-abundance plots for 31 Amazonian rain forest mosquito species. (a) Theoretical distributions of species abundance data (modified from Krebs 1989). Rank log-abundance distribution for mosquito species in (b) canopy and understorey habitats; (c) rainfall class Is (Intermediate season); (d) rainfall class ERs; (e) rainfall class LRs, and (f) rainfall class Ds.

assessment of spatial and temporal variation in this guild of host-seeking mosquitoes, many of which can transmit human pathogens. Thus, for instance, we show that only a few species have a clear preference for host seeking in the forest canopy, and present formal statistical support for this interpretation. We also show that species diversity, contrary to expectations, tends to be lower in the canopy than in the understorey. Our numerical estimates of species rich- ness and diversity (with the corresponding measures of uncertainty) open the possibility of comparative analyses with similar datasets from other locations and periods (Gotelli and Colwell 2001).

The effects of rainfall on mosquito abundance and richness were evident in our dataset. Diversity was higher (as measured by $S_{R}$ and $H^{\prime}$ ) during the rainy season, when no species was clearly dominant. Species-specific abundance patterns support the idea that 


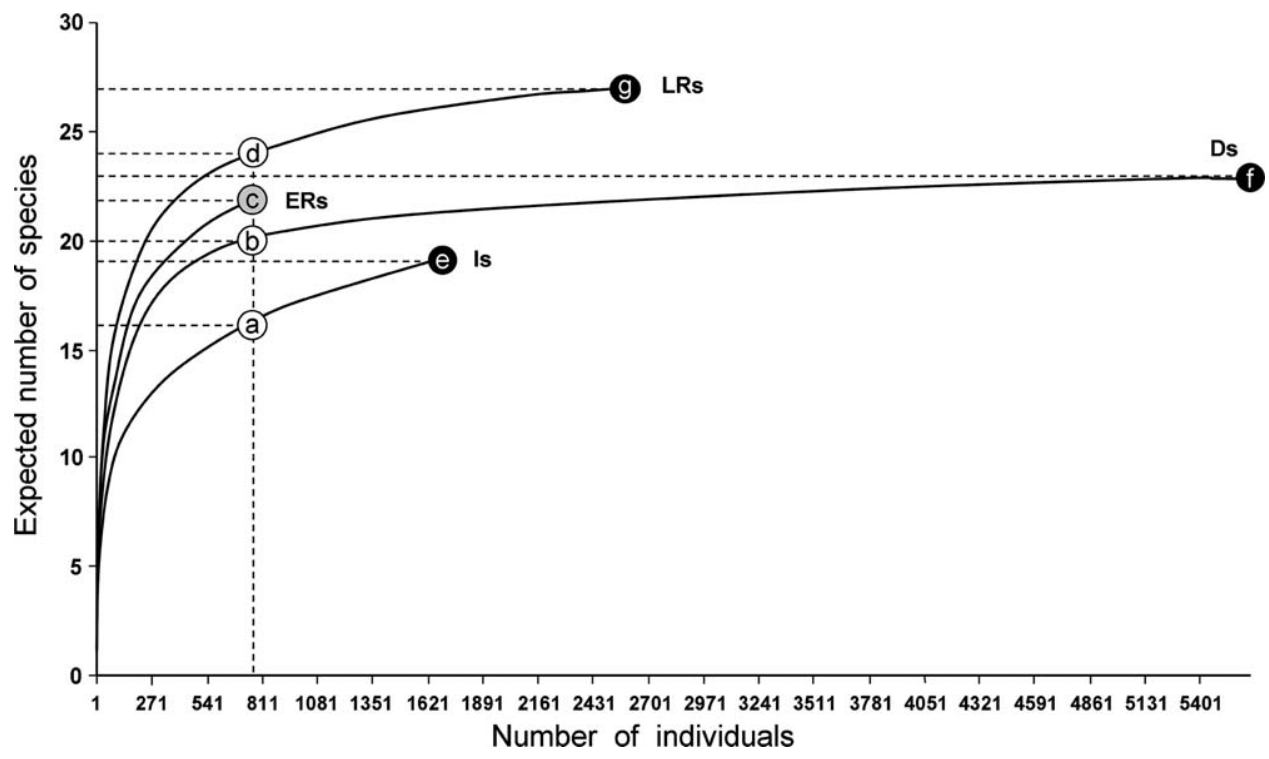

Fig. 3. Individual-based rarefaction curves for mosquito species in each of four rainfall classes. Species density is the estimated number of species in each rainfall class. Species richness (estimated number of species in each rainfall class given equal sample sizes) was rarefied to the number of individuals of the rainfall class with lowest mosquito abundance (ERs). Encircled letters indicate species richness ( $a, b, c$, and d) and species density (e, f, and g) (see Table 2). Species richness and density values are the same in ERs (c) (see text and Table 1 for details).

seasonality is the main driver of variation in the composition and structure of mosquito fauna in Amazonian rain forests (Consoli and Lourenço-de-Oliveira 1994, Lourenço-de-Oliveira and Luz 1996, Luz and Lourenço-de-Oliveira 1996, Tadei et al. 1998, Forattini 2002). These patterns are probably related to the availability of larval habitats, such as clean slow-running streams and ponds for most anophelines (including An. forattinii), temporary pools for many Culex species (including Cx. bastagarius), and small water collections on the ground or phytotelmata for many Aedini (including Ae. serratus and Ae. fulvus) (Consoli and Lourenço-de-Oliveira 1994, Hutchings and Sallum 2001, Forattini 2002). Rainfall patterns are also expected to be important for species (such as several

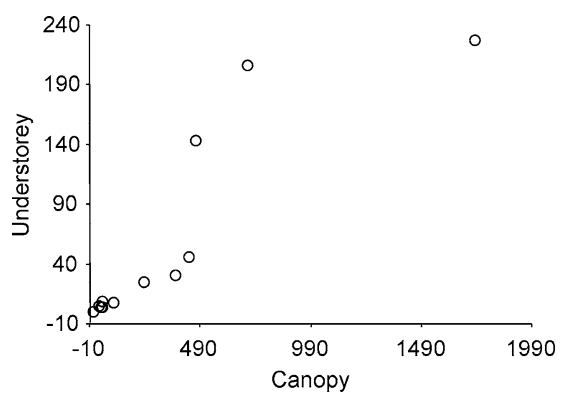

Fig. 4. Relationship between canopy and understorey monthly catches of An. forattinii host-seeking females. Understorey (nonpreferred habitat) catches increase proportionally to canopy catches only at low values $(<500$ individuals/mo). At higher values, the proportion of female mosquitoes in the nonpreferred habitat becomes disproportionately large.
Aedini) whose drought-resistant eggs only hatch after the end of the Ds; the reproduction of newly emerged adults leads to a peak of abundance in the LRs (Consoli and Lourenço-de-Oliveira 1994, Forattini 2002).

Vertical stratification of the rain forest mosquito fauna is expected to result from vertical variation in habitat traits. For instance, in tropical broadleaf forests there are light, temperature, and humidity vertical gradients; larval habitats, hosts, and resting sites are also differ across forest strata (e.g., Bates 1949, Yanoviak 1999). The amount (Erwin 2001, Haugaasen and Peres 2007) and diversity of vertebrate hosts available to female mosquitoes should be higher in the forest canopy (de Thoisy et al. 2003). We expected this higher resource diversity to result in a larger number of canopy-specialist species. Overall, our analyses showed no differences in the number of mosquito species caught in each habitat; richness and density estimates were similar or identical, and $87 \%$ of all mosquito species were collected in both canopy and understorey habitats. The data nonetheless suggested vertical variation in species composition: both $H^{\prime}$ and $H_{E}{ }_{E}$ values indicated that, despite higher absolute abundance, the host-seeking mosquito fauna may be less diverse in the forest canopy, where only five species were represented by over 100 individuals, versus 11 in the understorey. Rank log-abundance plots indicated that canopy catches match a log-normal distribution better than understorey catches do. Only two species (An. forattinii and An. shannoni) were clearly acrodendrophilic in our dataset, while five species were caught preferentially in the understorey. As a whole, these results suggest that blood-seeking females of a few, abundant mosquito species exploit 
habitat resources (hosts and, perhaps, also nectar sources and mating or resting sites) very efficiently in the canopy. However, understorey species composition, with more specialist taxa, and patterns of relative abundance, with no clearly dominant species, suggest that the partitioning of resources among species is more homogeneous in this habitat (Sugihara et al. 2003, Magurran 2004). The relative rarity of habitatspecialized taxa (particularly canopy specialists) was unexpected and calls for further investigation.

Adult mosquitoes fly across vertical forest strata (e.g., Deane et al. 1984). A host-seeking female mosquito can be attracted to a potential blood source at ranges between 7 and $30 \mathrm{~m}$, and mosquito trap performance is known to vary with bait size (Service 1993). Vertical mobility may therefore be enhanced by the presence of a large potential blood source such as a human being (Forattini et al. 1968). This effect can weaken the signal of vertical stratification in forest mosquito datasets, and obviously has a bearing on disease transmission dynamics. Plasmodium brasilianum (Gonder and von Berenberg-Gossler, 1908) is transmitted among platyrrhine monkeys by forest anophelines (Lourenço-de-Oliveira and Luz 1996, Fandeur et al. 2000). This parasite may infect humans too, causing quartan malaria (Contacos et al. 1963); there is currently solid evidence that $P$. brasilianum and P. malariae (Laveran, 1881) should be considered as a single taxon (see Fandeur et al. 2000). Our data show how one proven vector (An.forattinni) (Klein et al. 1991a,b; see Wilkerson and Sallum 1999) and one potential vector of this parasite (An. shannoni, a suspect vector of simian malaria; see Lourenço-de-Oliveira and Luz 1996) may leave their preferred (canopy) habitats and bite humans, suggesting that they can contribute to $P$. brasilianum/malariae transmission to humans in the Amazon (Scopel et al. 2004). Hemagogus spp., also considered canopy specialists (Pinto et al. 2009), maintain sylvatic yellow fever and Mayaro virus transmission among forest monkeys; however, the pathogens sporadically reach humans who walk into forested areas, probably because the vectors can also bite at ground level (Vasconcelos et al. 2001). Serological evidence suggests that there is a vertical gradient of yellow fever and Mayaro virus transmission intensity in the Amazon, with higher infection rates in canopy mammals (Talarmin et al. 1998), but ground-dwelling animals (such as the redrumped agouti) can also be infected (de Thoisy et al. 2003). We speculate that a relationship may occur between female mosquito density and host-seeking in nonpreferred habitats, perhaps mediated by host defensive behavior (Kelly 2001, Darbro and Harrington 2007).

In conclusion, most published studies on Amazonian mosquito vectors are merely descriptive (but see Nagm 2007, Johnson et al. 2008). Our results illustrate how assessing subtle changes in a highly diverse fauna ensemble may benefit from the joint consideration of single-figure metrics (e.g., $H^{\prime}, H_{E}{ }_{E}$ ), graphic analyses (e.g., rarefaction curves and rank log-abundance plots), and model fitting (Krebs 1989, Gotelli and
Colwell 2001). The results may be particularly relevant for understanding the life history of $P$. brasilianum/malariae (Scopel et al. 2004) and arboviruses (Vasconcelos et al. 2001) in forested landscapes. These and other vector-borne disease agents are of special concern in Amazonia, where humans live in close contact with potential pathogens and their hosts, vectors are abundant and hyper-diverse, and anthropogenic disturbance of the rain forest is increasing. In this situation, disease emergence (particularly of vector-borne zoonotic diseases) seems virtually unavoidable (Jones et al. 2008). We foresee that ecological studies on forest mosquito vectors will play a key role in enhancing our understanding of the fundamental drivers of disease emergence in the Amazon.

\section{Acknowledgments}

This work was supported by the Fiocruz-CNPq and Fiocruz-Fapeam agreements. We thank Gonçalo Ferraz for sharing his views on the use and abuse of diversity metrics in ecology. Comments by two anonymous reviewers substantially improved the original manuscript. This paper is contribution number seven of the Research Program on Infectious Disease Ecology in the Amazon (RP-IDEA) of the Instituto Leônidas e Maria Deane-Fiocruz Amazônia.

\section{References Cited}

Bates, M. 1949. The adaptations of mosquitoes to the tropical rain forest environment. Proc. Am. Phil. Soc. 93: 340-346.

Beaty, B. J., and W. C. Marquardt. 1996. The biology of disease vectors. University Press of Colorado, Niwot, CO.

Consoli, R.A.G.B., and R. Lourenço-de-Oliveira. 1994. Principais mosquitos de importância sanitária no Brasil. Editora FIOCRUZ, Rio de Janeiro, Brasil.

Contacos, P. G., J. S. Lunn, G. R. Coatney, J. W. Kilpatrick, and F. E. Jones. 1963. Quartan-type malaria parasite of New World monkeys trasmissible to man. Science 142: 676.

Cook, G. C. [ed.]. 1996. Manson's tropical diseases. W.B. Saunders, London, United Kingdom.

Darbro, J. M., and L. C. Harrington. 2007. Avian defensive behavior and blood-feeding success of the West Nile vector mosquito, Culex pipiens. Behav. Ecol. 18: 750-757.

Deane, L. M., J. A. Ferreira-Neto, and M. M. Lima. 1984. The vertical dispersion of Anopheles (Kerteszia) cruzii in a forest in southern Brazil suggests that human cases of malaria of simian origin might be expected. Mem. Inst. Oswaldo Cruz 79: 461-463.

de Thoisy, B., J. Gardon, R. A. Salas, J. Morvan, and M. Kazanji. 2003. Mayaro virus in wild mammals, French Guiana. Emerg. Infect. Dis. 9: 1326-1329.

Edman, J. D., and T. W. Scott. 1987. Host defensive behaviour and the feeding success of mosquitoes. Insect Sci. Applic. 8: 617-622.

Erwin, T. L. 2001. Forest canopies, animal diversity, pp. 19-25. In S. A. Levin [ed.], Encyclopedia of biodiversity, vol. 3. Academic, New York.

Fandeur, T., B. Volney, C. Peneau, and B. de Thoisy. 2000. Monkeys of the rain forest in French Guiana are natural reservoirs for $P$. brasilianum/P. malariae malaria. Parasitology 120: 11-21.

Fé, N. F., M.G.V. Barbosa, F.A.A. Fé, M.V.F. Guerra, and W. D. Alecrim. 2003. Fauna de Culicidae em municípios 
da zona rural do Estado do Amazonas, com incidência de febre amarela. Rev. Soc. Bras. Med. Trop. 36: 343-348.

Foley, D. H., L. M. Rueda, and R. C. Wilkerson. 2007. Insight into global mosquito biogeography from country species records. J. Med. Entomol. 44: 554-67.

Forattini, O. P., O. Souza Lopes, and E. X. Rabello. 1968. Investigações sobre o comportamento de formas adultas de mosquitos silvestres no Estado de São Paulo, Brasil. Rev. Saúde Pública. 2: 111-73.

Forattini, O. P. 2002. Culicidologia médica, vol. 2: Identificação, biologia, epidemiologia. Editora da Universidade de São Paulo, São Paulo, Brasil.

Gotelli, N. J., and R. K. Colwell. 2001. Quantifying biodiversity: procedures and pitfalls in the measurement and comparison of species richness. Ecol. Letters 4: 379-391.

Haugaasen, T., and C. Peres. 2007. Vertebrate responses to fruit production in Amazonian flooded and unflooded forests. Biodivers Conserv. 16: 4165-4190.

Holland, S. M. 2003. Analytic rarefaction 1.3. (http://www. uga.edu/ strata/Software.html).

Hutchings, R.S.G., and M.A.M. Sallum. 2001. Bionomics data for Anopheles (Anopheles) forattinii Wilkerson \& Sallum, 1999. Acta Amaz. 31: 699-701.

Hutchings, R.S.G., M.A.M. Sallum, R.L.M. Ferreira, and R. W. Hutchings. 2005a. Mosquitoes of the Jaú Park and their potential importance in Brazilian Amazonia. Med. Vet. Entomol. 19: 428-441.

Hutchings, R.S.G., M.A.M. Sallum, R.L.M. Ferreira, and W. Hutchings. 2005b. O acervo de mosquitos (Diptera, Culicidae) de Nelson L. Cerqueira na Coleção de Invertebrados do Instituto Nacional de Pesquisas da Amazônia, Manaus, Brasil. Rev. Bras. Entomol. 49: 15-28.

Johnson, M. F., A. Gómez, and M. Pinedo-Vasquez. 2008. Land use and mosquito diversity in the Peruvian Amazon. J. Med. Entomol. 45: 1023-1030.

Jones, K. E., N. G. Patel, M. A. Levy, A. Storeygard, D. Balk, J. L. Gittleman, and P. Daszak. 2008. Global trends in emerging infectious diseases. Nature 451: 990-994.

Kelly, D. W. 2001. Why are some people bitten more than others? Trends Parasitol. 17: 578-581.

Klein, T. A., J.B.P. Lima, and M. S. Tada. 1991a. Comparative susceptibility of anopheline mosquitoes to Plasmodium falciparum in Rondonia, Brazil. Am. J. Trop. Med. Hyg. 44: 598-603.

Klein, T. A., J.B.P. Lima, M. S. Tada, and R. Miller. 1991 b. Comparative susceptibility of anopheline mosquitoes in Rondonia, Brazil to infection by Plasmodium vivax. Am. J. Trop. Med. Hyg. 45: 463-470.

Krebs, C. J. 1989. Ecological methodology. Harper and Row, New York.

Lourenço-de-Oliveira, R., and S.L.B. Luz. 1996. Simian malaria at two sites in the Brazilian Amazon-II. Vertical distribution and frequency of anopheline species inside and outside the forest. Mem. Inst. Oswaldo Cruz 91: 687-694.

Luz, S.L.B., and R. Lourenço-de-Oliveira. 1996. Forest Culicinae mosquitoes in the environs of Samuel Hydroelectric Plant, state of Rondônia, Brazil. Mem. Inst. Oswaldo Cruz 91: 427-432.

Magurran, A. E. 1996. Ecological diversity and its measurement. Princeton University Press, Princeton, NJ.

Magurran, A. E. 2004. Measuring Biological Diversity. Blackwell Publishing, Oxford, United Kingdom.
Mathers, C. D., A. D. Lopez, and C.J.L. Murray. 2006. The burden of disease and mortality by condition: data, methods, and results for 2001, pp. 45-240. In A. D. Lopez, C. D. Mathers, M. Ezzati, D. T. Jamison, and C.J.L. Murray [eds.], Global burden of disease and risk factors. Oxford University Press/The World Bank, New York.

Nagm, L., J. F. Luitgards-Moura, C. S. Neucamp, F.S.M. Barros. N. A. Honório, P. Tsouris, and M. G. Rosa-Freitas. 2007. Affinity and diversity indices for anopheline immature forms. Rev. Inst. Med. Trop. São Paulo 49: 309316.

Natal, D., J.M.S. Barata, C.B.T. Lagos, and R. M. Rocha. 1992. Nota sobre culicídeos (Diptera: Culicidae) da bacia do rio Purus, Acre, Amazônia (Brasil). Rev. Saúde Pública. 26: 129-131.

Pinto, C. S., U.E.C. Confalonieri, and B. M Mascarenhas. 2009. Ecology of Haemagogus sp. and Sabethes sp. (Diptera: Culicidae) in relation to the microclimates of the Caxiuanã National Forest, Pará, Brazil. Mem. Inst. Oswaldo Cruz 104: 592-598.

Scopel, K. K., C.J.F. Fontes, A. C. Nunes, M. F. Horta, and E. M. Braga. 2004. High prevalence of Plasmodium malariae infections in a Brazilian Amazon endemic area (Apiacás-Mato Grosso State) as detected by polymerase chain reaction. Acta Trop. 90: 61-64.

Service, M. W. 1993. Mosquitoes (Culicidae), pp. 120-240. In R. P. Lane and R. W. Crosskey [eds.], Medical insects and arachnids. Chapman \& Hall, London, United Kingdom.

Sota, T., E. Hayamizu, and M. Mogi. 1991. Distribution of biting Culex tritaeniorhynchus (Diptera: Culicidae) among pigs: effects of host size and behaviour. J. Med. Entomol. 28: 428-433.

Sugihara, G., L.-F. Bersier, T.R.E. Southwood, S. L. Pimm, and R. M. May. 2003. Predicted correspondence between species abundances and dendrograms of niche similarities. Proc. Natl. Acad. Sci. U.S.A. 100: 5246-5251.

Tadei, W. P., B. D. Thatcher, J.M.M. Santos, V. M. Scarpassa, I. B. Rodrigues, and M. S. Rafael. 1998. Ecological observations on Anopheline vectors of malaria in the Brazilian Amazon. Am. J. Trop. Med. Hyg. 59: 325-335.

Talarmin, A., L. J. Chandler, M. Kazanji, B. de Thoisy, P. Debon, J. Lelarge, B. Labeau, E. Bourreau, J. C. Vié, R. E. Shope, and J.-L. Sarthou. 1998. Mayaro virus fever in French Guiana: isolation, identification, and seroprevalence. Am. J. Trop. Med. Hyg. 59: 452-456.

Vasconcelos, P.F.C., A.P.A. Travassos da Rosa, S. G. Rodrigues, E. S. Travassos da Rosa, N. Dégallier, J.F.S. Travassos da Rosa. 2001. Inadequate management of natural ecosystem in the Brazilian Amazon region results in the emergence and reemergence of arboviruses. Cad. Saúde Pública 17: 155-164.

Wilkerson, R. C., and M.A.M. Sallum. 1999. Anopheles (Anopheles) forattinii: a new species in Series Arribalzagia (Diptera: Culicidae). J. Med. Entomol. 36: 345-354.

Yanoviak, S. P. 1999. Community structure in water-filled tree holes of Panama: effects of hole height and size. Selbyana 20: 106-115.

Zar, J. H. 1999. Biostatistical analysis, 4th ed. Prentice Hall, Upper Saddle River, NJ.

Received 2 March 2009; accepted 4 October 2009. 